\title{
Several Times We Could Have Avoided Crisis and Conflict in Organization
}

\author{
Peter Okpamen \\ Ambrose Alli University, \\ Ekpoma-Edo State, Nigeria
}

\section{Doi:10.5901/jesr.2013.v3n5p53}

\begin{abstract}
Crisis and Conflict are manifestation of human activities resulting from differences in their behaviour, belief, culture, etc. The consequence often results in a breakdown in organization's activities. Perhaps, the bone of contention here is that of the inability of the organization to put in place preventive measures or rather have an efficient communication network model to relate with employees on a regular basis. Often times management are opportune to avoid these conflicts before they occur, rather they adopt "I don't care attitude" when dealing with issues relating to conflict. The extent to which we can avoid crises therefore depends on the management style of individual leader. Until the organization concentrate on a collective effort at preventing crisis and conflict, the goal of achieving peace and harmony in the workplace will continue to be a mirage.
\end{abstract}

\section{Introduction}

I wish to aver here that crisis and conflict is as old as the organization itself, but sometimes it could have been avoided before it arise, provided there are functional structures in place to always prevent or manage it when it occurs. It is however uncommon to see managers investing in conflict prevention as they prefer to deal with it at the eleventh hour, and hence a higher cost to the organization.

Essentially, conflict is an inevitable aspect of human interaction, an unavoidable concomitant of choices and decisions... The problem then is not for us to identify the frustration of seeking to remove inevitability but rather of trying to keep conflicts in bounds. For the avoidance of doubt, we should not be so allergic to conflicts that we become paranoid. Every form of interaction among human beings and groups can generate conflict. Conflict should be viewed as the spice of the organization. It test the fragility or otherwise of the organization and creates the basis of future amelioration or adjustments. However, conflicts beyond certain thresholds are detrimental to the survival of the organization, because they threaten the consensual basis of the organization. Perhaps, it is also imperative to suggest here that conflicts which emanate from non-recognition of the claims of others to issues of conflict (for example excluding others from events or decision taking) could be very dangerous for the organization. Such conflicts mobilize total loyalties of the people and tend to defy all attempts at effecting desirable compromises. The events that often generate conflict in organization could be traced to perceived incompatibility among the various groups in the organization. On the other hand, conflicts which result from the nature of distribution are less dangerous to the survival of the organization. In this case the claims of others are recognized, and hence the only issue of conflict is over the items of conflicts (such as how the 
resources in the organization are allocated) are shared or how adequate compromises are struck between competing resources.

The second issue of this paper is how we deal with causality. Finding causes of conflicts could be very difficult. As any good social scientist would explain, tracing causality is very difficult. As an illustration, to what extent is the ostensible reason of "bad food" the cause of students' riot in a given university? Were the London riots of 2011, a consequence of neglect of the youths? Or were these events the result of multi-variable causation and the reason given mere verisimilitudes? Conflicts may be caused by actions which lead to mutual mistrust, polarization of relations, and/or hostility among groups in apparently competitive interaction within the organization. They may even result from frustrations arising from unsatisfied needs- physical, psychological, social, and economic and others. Conflicts may also arise from explosion of identity as employees begin to ask for greater participation and rights. Threatened identities of groups have also led to conflicts in organization. Seeming cultural incompatibility among groups with different communication styles could generate conflicts. In addition, demonstrable and/or perceived inequality and injustice expressed through competitive variables and cultural frameworks, have been known as potent causes of conflicts, as groups react to the perceptions of the situation.

The principle of power and perceived domination by one group or the other in the organization can lead to the frustration and disenchantment/alienation of one group or the other from the organization. Against this backdrop it is believed that it is difficult to adequately identify causes of conflict in contemporary organization.

Basically, the word conflict is a Latin word which refers to 'clash', 'fight' or 'confrontation' amongst parties whose means or ends are incompatible. In plain or simple English, crisis refers to a "time of grave danger, difficulty or uncertainty when problems must be solved or important decisions must be made." It is possible to have a violent conflict or a non-violent conflict. This is often manifesting. Similarly, there may be latent conflicts, gestating for a long time, without simmering to the surface. In the history of many organizations, many unattended latent conflicts explode into manifest and violent conflicts. It is therefore imperative that since conflict is inevitable, it can be managed. Conflict management simply put, refers to interventionist "efforts towards preventing the escalation and negative effects, especially violent ones, of on-going conflicts." These conflicts could then be reduced, downgraded, contained or coped with, especially since conflicts are hardly completely resolved. In other words, conflict management in organization is a continuous process. Similarly, depending on the parties to the conflict, conflict managers may also vary.

In this paper therefore, we have argued that while it is difficult to adequately trace the causes of conflicts and crises in organization, it may be safe to argue that organizational conflicts are historical and multidimensional. It is also believed that frequent conflicts in organization could undermine mutual confidence among management and the various groups in the organization. We have also attempted to demonstrate through quantitative survey and conflict symptom indicator model approach that conflict could sometimes be avoided within the organization. Apart from section I, the paper is adumbrated into section II which discusses conflict in organizational context, section III contains a discussion on how these conflicts could have been avoided, while section IV is on the subject matter; towards conflict prevention, management and resolution, while section $v$ contains the methodology used in this research; and finally section $\mathrm{V}$ brings the analysis to a close with a concluding remark.

\section{Conflict in Organizational Context}

Broadly speaking, an organisation is made up of groups and individuals of different views, religious, cultural, political and social interest and preferences, which must be summed up by management to achieve its organisational goals. The issue at stake is not to try to eradicate conflict, but how to reduce it to the barest so that it does not interfere with organisational goals. Conflict should not be 
seen as destructive; but should be seen as part of management challenges and a creative element for advancement. It is a means through which we can achieve our social values, welfare, security, justice, etc. As the organization become increasingly open and diverse, its nature of conflict becomes more complex. In view of this development conflict in organization becomes inevitable and perhaps even more desirable for a balance in the organization. The benefit of people of different background working together implies there is bound to be conflict management. (Tjosvold 2008: 19).

Essentially, in all aspects of human endeavour, there are conflicts. This invariably implies that we definitely cannot avoid conflict completely, be it at home, office, or otherwise. The implication of conflict for organizational development has over the years extended further than ever thought before as the co-existence between home blurs and work, and organization experiment with flatter and more decentralized structures. Furthermore, the intensity of conflict has been a function of the organization's size and its diverse nature. To work together in an organization therefore suffice to say that conflict is partially unavoidable, but desirable to some extent: In other words, "working together in an organization is to be in conflict; and taking advantage of the benefits of working together in group requires conflict management" (Tjosvold 2008 : 19). This is perhaps the singular reason as to why conflict management is receiving a wider attention from conflict managers and policymakers across the world.

However, an organisation requires a peaceful atmosphere embraced by compromise and understanding between management and employees. In view of this development, there is bound to be high productivity always and a positive development in the organisation. Present day organisations unlike in the past are often harassed by individual unrest, threat of workers going on strike as a result of dissatisfaction in a new policy or improved working condition; coupled with demand for pay rise as a result of increasing financial squeeze. If this re-occurring decimal is not brought under control, it could be disastrous in future and could create unnecessary economic loss to the organisation and the society in general. It sometimes sum up to strikes, blackmail, stress and loss of productivity.

The fact that these disruptions are now very frequent amongst organisations calls for concern as to whether appropriate conflict resolution methods are in place in these organisations. Why should a manager wait for 48 hours to a 'strike action' before adopting a "fire brigade approach" to dealing with conflict? When you peruse through some companies accounts, you discover that they do not specify cost of conflict for reasons best known to them. The basic truth is that most managers do not even know the sources and causes of conflicts in their organisation. If managers are aware of the cost of conflict, they will certainly take appropriate measure to check cost in the interest of the going concern of the organisation. However, the ability of an organisation to manage conflict effectively brings to focus a transparent view of its strength and weakness of some policies. In this study therefore, there is need to give considerable attention to the problems of conflict management, sources and its consequence on organisation's operations especially to managers.

\subsection{Types of conflict in organization}

Broadly speaking, there are different types of conflict in organization; while some are internal, others could be external. In most cases internal conflicts can be avoided or minimised; but management is at the mercy of the external conflicts. Below is a brief description of some of the perennial conflicts in organization.

i. Conflict involving the individual: This arises when the individual is faced with uncertainty as to what work he/she is expected to carry out. It is often referred to as intra-individual conflict.

ii. Another form of conflict is the conflict involving individuals in the same organisation; otherwise known as interpersonal conflict arising from personality differences. Conflict 
among individuals and groups do exist in an organisation. How the individual cope with the pressures from the work group determines the extent.

iii. Another type of conflict is a conflict among groups in the same organisation. This is also known as an inter-group conflict involving line staff and labour management.

iv. Conflict involving organisations in the same line of business competing with one another. In this form of conflict, the organisations involved could be at "price war" with each other in terms of pricing for their products. In addition, there are also conflicts that exist among individuals in different organisation.

v. Internal conflict: This involves people within the organisation in the same level of authority having disagreement as to what should be done. Another form could be vertical conflict which involves acceptance of authority as a result of difference between the chain of command from the managers. This type of conflict is very common in a bureaucratic setup.

vi. System conflict: Basically, an organisation is a system made up of different parts. When the various parts are not interacting effectively, then we conclude that system conflicts exist.

Lipsky and Seeber (2006) maintained and classified organizational conflict into three types: First, are the Latent and Manifest disagreements- this implies "an organizational friction capable of generating a mismatch in expectations of the exact course of action for an employee or group of employees (Lipsky et al. 2003: 8). Second, are workplace disputes- this refers to conflict that culminate into formal complaints, agitations and charges" (Lipsky and Seeber 2006:363). Finally, is the aspect of litigation- which involves lawsuits filed before regulatory agencies against the employer or employee. By and large, there has been a general consensus within the communication field indicating that conflict principally anchors on three factors; which include incompatibilities, expressed struggle and interdependence between two or more parties (Putnam 2006)

\subsection{Sources of conflicts in organization}

Theoretically, potential sources of conflict are generally traced to the basic assumptions underlying group interaction. The group behaviour depends on the perception of the stakes involved and the perception is that an agreement may go either way in a conflict. Within the group is a role conflict that often stems from limited resources, organisational environment, individual difference and role differentiation. Conflicts have different sources but according to Tjosvold, "the source of conflict should not be a concern, instead it is how people manage it that determines its course and outcomes". Communication has been found to play an integrative role in conflict and conflict management (e.g., Putnam 2006; Aula \& Siira: 2007). However, some of the potential sources of conflict include:

Competition over scarce resources in the organisation: The various departments in the organisation compete over the available resources. For instance, conflict may occur between marketing manager and the production manager because their policies and interest often differs. While the production manager is interested in producing as much as possible, the marketing manager is interested in how much of the products can be sold to maximise profit for the organisation. The way forward is to set-up a resource allocation policy/strategy through the application of Linear Programming technique (Simplex Method).

Individual differences in perception: Organisation is a system or a micro representation of the larger society. It encompasses people with divergent views, culture, thinking and different ways of doing things. To deal with such a situation, the views of everyone in the organisation should be respected all the time because you never can tell whose view can lift the organisation to a greater height. 
Ambiguity of managers in authority and responsibility. Some managers are filled with ambiguity when it comes to the issue of authority and responsibilities. This does not go down well with employees because they feel more confused. It is necessary to put in place the relevant authority, the roles and responsibilities of the workers to avoid ambiguity.

Personality clash as a result of different personality traits. There is need to respect the personality of the individual and avoid bringing it into place of work. Incidence of personality could affect the organisational goals, as well as its productivity level.

Contravening laid down policies and procedure: This often leads to frequent clash between the boss and the subordinate; and this can portray a danger for the organization. If the issue is not properly handled, it can lead to frequent turnover of workers and a cost to the organisation.

External source of conflict on the other hand comprise government's industrial and economic policies. The nature of labour legislation, unpatriotic and unethical behaviour of the political and economic classes, national economic management and general distribution of wealth and power in the society are also sources of external conflicts.

Maslow, in his "theory of motivation", attempts to explain the reasons why workers feel dissatisfied despite available comfortable condition? Maslow's submission portrayed the fact that hierarchy of needs must be sequentially followed and satisfied. These needs are cumulative and the satisfaction of one leads to the domination of the next need. So long, anyone of these needs remain unsatisfied; there is always a room for discontent.

\subsection{Positive and destructive nature of conflict in organization.}

Conflicts have both good and bad side and could be positive or negative in nature. Some schools of thought believe that a situation where conflict appears very low is an indication that the workers are not willing to "rock the boat". Instead of passive resistance, civil disobedience, the passive workers accept things the way they are. So many things are taken for granted, especially issues and behaviours that could stir people up to do good and better job. In addition, the workers tolerate each other's weakness and lack lustre performance. Managers saddled with such situations finds out that stimulating competition and conflict could have a galvanizing effect. From earlier discussion above, conflict is sometimes necessary to stimulate changes in positive direction. Conflict is capable of opening up an issue in a confronting manner. It is also an avenue to improve problem-solving quality. Conflict, apart from strengthening relationship when creatively resolved, also provides more spontaneity in communication. The other side of the coin regarding conflict in organisation could be more destructive than you can ever imagine. Conflict is capable of diverting an organisation from its real task when the workers' morale is destroyed. Conflict can deepen differences especially between an employee and a boss who believe that issuing threat/query is the ultimate. A right thinking manager should not see query as a means of resolving crisis. The use of query should be seen as a last resort. However, conflict could polarize the individual and group. At the end of the day, it could produce an irresponsible behaviour. Conflict can also decrease productivity and creates suspicion and distrust between the union and the management.

\subsection{The cost of conflict in organization}

Broadly speaking, the opportunity cost of conflict to organization is the real cost of not dealing with conflict or the foregone alternatives which are detrimental to the organization's stability and survival strategy. It is an establish fact that, the 'Biblical Noah' built an ark when it was not raining. This portrayed him as one of the best proactive managers (planner) that ever lived on earth. In the same vein, a manager that plan towards conflict management without a recognition for the implication of Information Technology in dealing with conflicts, obviously plans to fail in future. Some of the real costs to the organization include: 
Loss of output: Conflict that is allowed to escalate to an uncontrollable extent could lead to loss of output to the organization. Oftentimes, some managers prefer to wait for workers to embark on industrial action before going into negotiation. This is not a desirable way to manage conflict because at the end of the day, the production will suffer a set back and record loss of output to the organization.

Damage to plant and materials: Conflict sometimes leads to damage of plants and materials, especially to raw materials that have expiring dates. A plant that was met to run for 24 hours could break down due to disruption.

Clean up cost after the conflict: As a result of break in the system of operation resulting from the aftermath of the conflict, the organization may be saddled with clean up cost which was not part of the initial budget of the organization.

Extra overtime: In order to meet up with the demand of its customers, the organization might have to pay the extra cost to the workers engaged in more hours than the require labor hours.

Recruitment/hire a replacement worker (cost of training etc): There are times where the conflict may result in the workers withdrawing their services to the organization or rather organizations with frequent conflicts are likely to experience high labor turnover all the time. It implies the organization will rely on recruitment or hiring of workers all the time. In view of this development, the organization is left with no choice than to pay the cost of hiring and training of new personnel.

Loss of 'goodwill' from the workforce and customers: As earlier mentioned above, frequent conflict between workers and management, coupled with lack of trust for the management could lead to loss of goodwill from the workforce. The customers no doubt will also loss confidence in the organization, and this might in- turn affect investor's confidence in the management.

Legal costs/fines: Sometimes conflict can lead to termination of a worker's appointment from the organization. Should the worker decide to seek redress from the law court, the organization is likely to pay a legal cost to pursue the case in court and some fines from the court.

Changes in insurance premium: Conflicts sometimes affect the level of premium paid by an organization. An organization with frequent conflict is likely to pay more premiums because the insurance company will base its rate on the company's conflict history.

Investigation of cause and preventing repeats: When a manager wait for conflict to engulf his organization before reacting, he is likely to set up a committee to investigate the remote cause of the crisis and to come out with a recommendation on how to prevent future occurrence. The cost of this investigation will be on the organization.

Distress to colleagues: Whenever there is a conflict in an organization that involve some members of the workforce, it will definitely have adverse effect on the other members of the workforce because of the principle of "esprit-de-corp."; an "injury to one is an injury to all". The other workers may be distressed because they don't know who might be the next victim.

\section{Several Times We Could Have Avoided Conflict}

In most cases, management are opportune to avoid conflicts before they occur, rather they prefer to adopt "I don't care attitude" in handling conflict issues. The extent to which we can avoid crises therefore depends on the management style of individual leader. However, should the underlisted factors been taken into consideration, conflict to a large extent could have been avoided or minimised by conflict managers. 


\subsection{The Emergence of Early Warning Signals}

Because managerial elites are not committed to resolving the problems of organizational conflicts, they are unprepared for future cases of unions' strike. Having experienced these strikes and conflicts before, one would expect each management to have a well equipped and manned Conflict Management Unit. This unit should have data on conflicts analyzed and provide early an early warning signal to managers. It is an established fact that not all conflicts can be predicted because human behaviour can also be spontaneous or instinctive in reaction to external provocations. To deal with such situation, conflict management unit of the organization can always hold regular seminars in order to ascertain facts.

The conclusion here is that an early warning does not exist in many organizations and there is need to put one in place. It should be noted that an early warning mechanism or system is not in place, until an early warning has been fed into the system and appropriate responses elicited as a result of such warning.

Organizations must thus establish an active Conflict Management Unit to help provide proper information, identification and policy options, from which appropriate responses can be undertaken. This also involves training appropriate staff for these units. Very many organizations treat security issues too carelessly and trivially.

\subsection{Management Sensitivity Nature in Decisions and Policies}

Management is hereby advised to always be sensitive, fair and just in their decisions and policies. It is not ideal for management to be a conflict-generator, nor should management overheat the already charged "bone of contention" through hurried rehashed and unthought-out policy because it suits the interest of a few people either in management or who have influence over management. After all, good governance entails catering for the interest of the majority while protecting the interest of the minority.

\subsection{Maturity of Leaders}

Leadership in organization is not about privileges to loot funds or push personal interest to the disadvantage of the groups or employees. Leadership is responsibility, an obligation to demonstrate commitment, integrity, honesty and decency in handling the affairs of heterogeneous groups in the organization. The speeches and utterances of managers before, during and after conflicts often indicates that they do not have patience, understanding, honesty, maturity and tolerance, which are marks of good leadership. It is even worse when these leaders in organization manipulate ethnic identity for their selfish ends. Mature leaders in organization must treat their employees with respect and do not talk down on them. Managers must encourage mutual respect even in context of vehement disagreement among the groups.

If necessary a conference of all the groups takes place in order to learn the values of tolerance and accommodation without any act of racism in the work place. Agreed this will take a long time to achieve, but we must not underrate it.

\subsection{Mutual Respect and Recognition of Demands of Others}

Broadly speaking, many of the conflicts we have witnessed emerged from lack of mutual respect for one another within the organization. We cannot all be the same. We must realize that even within single group, there are differences in perspectives and opinions. After all, disdain and arrogance (bankrupt of content) are often marks of inferiority complex.

Similarly, parties at dispute must be able to dialogue with one another, no matter how difficult. Conflict managers should respect and recognize the demands of others in a competitive 
context even if they disagree with such claims. The consequence of non-recognition of claims could generate major conflicts which often affects loyalties of the group. In most cases recognition of union's demands, while disputing the nature of the demands, creates a basis for meaningful discussion. The 'bone of contention' is more relevant rather than looking at the illegitimacy of the demands. In order words, management should not wait until the competitive process turns into sour interactions among the disputants.

\subsection{Platform for Regular Communication and Understanding}

Perhaps one area of urgent action is to establish frameworks for constant dialogue and understanding among management, union members and employees within the organization as a first step. This is very important because conflict can easily spill-over across the board.

\section{Towards Conflict Prevention}

While the management of conflict is important and continuous in the lives of organizations, it is even more important to put in place adequate mechanisms for conflict prevention. This idea has been mentioned earlier, but it is important to realize that conflict prevention, management and resolution are cardinal functions of organization and must be taken seriously. The use of force or threat by conflict managers should not be seen as a viable way to deal with conflicts. There is a limit to the use of force or threat as this might only provide a temporary order. In order words, it does not tackle the source of conflict. In the light of the above, one effective way of preventing and managing conflict is to invest in resources so as to get to the root cause of problems-difficult, as these may be. Treating symptoms may cost the organization heavily.

The use of closed circuit television can act as a support to the following model; otherwise known as 'conflict symptoms indicator model' (CSIM). There is no use having CCTV in the organization and not put into proper use to help prevent or avoid conflict. If 'CCTV' is properly adopted by managers to monitor the under listed problems properly, there is no doubt it will go a long way in helping managers to see the dangers ahead in the organization. It is a matter of employing competent persons who are management inclined and psychologically skilled to monitor activities, operations and workers behaviour at work place. When any of these symptoms is diagnosed in time, then the manager can act towards amendment. The model appears trivial but pro-active managers who mind to adopt this model will find things easy and will always be in harmony with the workforce.

i. Lower job efficiency: When job efficiency begins to diminish, then the manager must know that there is something wrong somewhere that requires an urgent attention.

ii. Unusual behaviour: When you begin to notice funny behaviour from your workers, then you need to interact with that worker in order to help him out of his problem. It's possible the problem is coming from his home and it is the duty of the manager to notice this and address the issue as they come, before it leads to crisis in the organisation.

iii. Spasmodic work pattern: Also, when the worker begins to carry out his responsibilities in a spasmodic manner, then you know that there is a danger within because no right thinking worker will work in that manner.

iv. Confusion: When you notice frequent confusion on the part of your worker, there is need to interact with him to know the cause of his confusion. It is possible that the job design or description is not clear to the worker.

v. Friction with other employees: Workers having frequent frictions with colleagues are more likely to produce conflict within the organisation. Such workers should be placed under constant surveillance. 
vi. Lack of concentration: This is also an agent of conflict because a worker who constantly looses concentration in workplace is more likely to plunge the organization into conflict.

vii. Increase absenteeism and on-the-job absenteeism: Frequent absenteeism from workplace and on-the-job is a symptom of conflict, and could be detrimental to the organization

\section{Methodology}

Essentially, primary data was used in this research, and we have used a simple structured questionnaire in this research to seek the views of respondents on what they think about the possibility of avoiding conflicts in their organization. In particular, Balfour Beatty Group, London was adopted for the case study and the respondents were chosen from three arms of the company (rail workers, civil engineering, and building/construction). A sample size of about 500 workers or more in each department was chosen in order to achieve a true representation and desired objective. In each category the respondents were asked the following:

\subsection{Questionnaire question:}

\subsubsection{Do you believe that several times conflict can be avoided in your organization?}

Below is a representation of the responses from the respondents.

\begin{tabular}{|l|c|c|}
\hline Res/Par. & YES Response & NO Response \\
\hline Rail workers & 232 & 168 \\
\hline Civil/engineering & 260 & 240 \\
\hline Building/construction & 197 & 203 \\
\hline
\end{tabular}

Source: Researcher's field work

\subsection{Hypothesis}

The following hypothesis was adopted to determine if there is a significant difference in the true proportion of the respondents that answered YES and respondents that answered No.
Ho (null):
$\mathrm{P}$ (YES Response) $=\mathrm{P}$ (NO Response)

$\mathrm{H} 1$ (alternate): $\quad \mathrm{P}$ (YES Response) $\neq \mathrm{P}$ (NO Response)

\subsubsection{Test of Hypothesis}

\begin{tabular}{|l|c|c|c|c|}
\hline Rea/par & YES & NO & Total & Proportion \\
\hline Rail workers & 232 & 168 & 400 & 0.31 \\
\hline Civil/engineering & 260 & 240 & 500 & 0.38 \\
\hline Building/construction & 197 & 203 & 400 & 0.31 \\
\hline Total & 689 & 611 & 1,300 & 1 \\
\hline Proportion & 0.53 & 0.47 & 1 & \\
\hline
\end{tabular}

Note that the first table above is a $3 \times 2$ contingency.

Now suppose we denote the expected number by eij, then from the table above we have that;
$\mathrm{n} 11=232$,
$\mathrm{n} 12=168$
$\mathrm{n} 21=260$,
$\mathrm{n} 22=240$ 


\begin{tabular}{|c|c|c|c|}
\hline \multicolumn{4}{|c|}{$\mathrm{n} 31=197, \quad \mathrm{n} 32=203$} \\
\hline \multicolumn{4}{|c|}{$\mathrm{e} 11=(\mathrm{n} 1 . \mathrm{n} .1) / \mathrm{n}=0.31 \times 689=213.6$} \\
\hline $\mathrm{e} 21$ & $2 . n .1) / n$ & $=0.38 \times 689$ & $=261.8$ \\
\hline $\mathrm{e} 31$ & 3.n.1)/n & $=0.31 \times 689$ & $=213.6$ \\
\hline $\mathrm{e} 12$ & 1.n.2)/n & $=0.31 \times 611$ & $=189.4$ \\
\hline $\mathrm{e} 22$ & $2 . n .2) / n$ & $=0.38 \times 611$ & $=232.2$ \\
\hline \multicolumn{3}{|c|}{ Rail (respondents): } & $=189.4$ \\
\hline $\begin{array}{l}\text { Rall } \\
\text { O: }\end{array}$ & $\begin{array}{c}\text { ondents } \\
232\end{array}$ & O: & 240 \\
\hline E: & 213.6 & E: & 189.4 \\
\hline O-E: & 18.4 & O-E: & -21.4 \\
\hline \multicolumn{4}{|c|}{ Civil/engineering (respondents): } \\
\hline O: & 260 & 0: & 240 \\
\hline E: & 261.8 & E: & 232.2 \\
\hline O-E: & -1.8 & O-E: & 7.8 \\
\hline
\end{tabular}

Building/construction (respondents):

$\begin{array}{llll}\text { O: } & 179 & \text { O: } & 203 \\ \text { E: } & 213.6 & \text { E: } & 189.4 \\ \text { O-E: } & -16.6 & \text { O-E: } & 13.6\end{array}$

$$
\begin{aligned}
& X^{2}=\sum_{j=1}^{2} \sum_{\mathrm{i}=1}^{3} \frac{\{\mathbf{o i j}-\mathbf{e i j}\}^{2}}{\mathrm{eij}} \\
& =\frac{(o 11-e 11)^{2}}{e 11}+\frac{(o 21-e 21)^{2}}{e 21}+\frac{(o 31-e 31)^{2}}{e 31}
\end{aligned}
$$$$
+\frac{(o 12-e 12)^{2}}{e 12}+\frac{(o 22-e 22)^{2}}{e 22}+\frac{(o 32-e 32)^{2}}{e 32}
$$$$
X^{2}=\frac{(18.4)^{2}}{213.6}+\frac{(-1.8)^{2}}{261.8}+\frac{(-16.6)^{2}}{213.6}+\frac{(-21.4)^{2}}{189.4}+\frac{(7.8)^{2}}{232.2}+\frac{(13.6)^{2}}{189.4}
$$$$
=1.585+0.012+1.290+2.418+0.262+0.977
$$

$\frac{X^{2}}{C}=6.544$

But degree of freedom $(\mathrm{df})$ is: $(r-1)(c-1)=(3-1)(2-1)=2$; at 0.05 level of significance we have;

$$
\begin{aligned}
& \frac{X^{2}(a)}{K-1}=\frac{X^{2}(0.05)}{3-1}=\frac{X^{2}(0.05)}{2}=\frac{X^{2}}{t} \\
& \frac{X^{2}}{\boldsymbol{t}}=\mathbf{5 . 9 9 1}
\end{aligned}
$$

\subsection{Remark:}

Since $\frac{X^{2}}{C}>\frac{X^{2}(a)}{k-1} ;$ it implies a rejection of the null hypothesis. 
Consequently, there exists a significant difference in the true proportion of people in the organization favouring YES over NO answer. This implies that a significant percentage of the workers are of the opinion that several times crisis in organization could actually be avoided, especially when there is harmony amongst management, union, and employees.

\section{Concluding Remark}

By and large, management of conflict in general has been demonstrably below average. Despite the numerous conflicts we have had in the past and present, there is hardly any evidence to conclude that conflict managers have learnt from experience or lesson; and management is often caught unaware. There is hardly any serious effort at establishing a data bank of conflicts and funding related departments to carry out analysis. Consequently, organization responses are therefore ad hoc and stereotypical. A functional early warning system, properly funded and managed could help organizations to prevent conflicts, or at least, manage emerging conflicts and crises effectively and efficiently. I believe most of the conflicts in organization are caused by management, because there is hardly any room for effective preventive measures in place, and most managers adopt a "fire brigade approach to dealing with situations," by waiting for the conflict to reach a crisis point. Management therefore must stop playing the role of conflict generators, and move forward to help employees in the organization re-establish mutual confidence amongst themselves as they struggle to build a strong, productive, and viable organization in this ever challenging global economy.

\section{References}

Aula, P., and Mantere, S. (2008) Strategic Reputation Management: Toward a Company of Good. New York: Routledge..

Lipsky, D.B., and Seeber, R.L. (2006) 'Managing Organizational Conflicts', in J.G. Oetzel and S. TingToomey (eds.) the Sage Handbook of Conflict Communication: Integrating Theory, Research, and Practice. Thousand Oaks, CA: Sage, pp. 359-390.

Lipsky, D.B., Seeber, R.L., and Fincher, R.D. (2003) Emerging Systems for Managing Workplace Conflict: Lessons from American Corporations for Managers and Dispute Resolution Professionals. San Francisco, CA: J ossey-Bass.

Oxford advanced learner's dictionary, 8th edition. By A .S, Hornby - Oxford University Press (2010) Paperback - 1796 pages - ISBN 019479900X

Putnam, L.L. (2006) 'Definitions and Approaches to Conflict and Communication', in oetzel, J.G., and Ting-Toomey, S. (eds.) the Sage Handbook of Conflict Communication: Integrating Theory, Research, and Practice, Thousand Oaks, CA: Sage, pp. 1-32.

Putnam, L.L., and Boys, S. (2006) 'Revisiting Metaphors of Organizational Communication', in Clegg, S.,Hardy, C., and Nord, W. (eds.) The Sage Handbook of Organizational Studies (2nd ed.) London: Sage,pp. 541-576.

Tjosvold, D. (2008) 'The Conflict-positive Organization: it depends upon us', Journal of Organizational Behaviour, Vol. 29, pp. 19-28.

http://www.nordicom.gu.se/common/publ_pdf/321_aula_siira.pdf 
